\title{
Motor Activity in Adult Patients with Attention Deficit Hyperactivity Disorder
}

\author{
Ole Bernt Fasmer ${ }^{1,2,3} \bowtie$, Kristin Mjeldheim ${ }^{4}$, Wenche Førland ${ }^{5}$, Anita L. Hansen ${ }^{6}$, \\ Steven Dilsaver ${ }^{7}$, Ketil J. Oedegaard ${ }^{1,2,3}$, and Jan Øystein Berle ${ }^{1}$ \\ 1'Division of Psychiatry, Haukeland University Hospital, Bergen, Norway \\ 2Department of Clinical Medicine, Section for Psychiatry, University of Bergen, Bergen, Norway \\ ${ }^{3}$ K.G. Jebsen Centre for Research on Neuropsychiatric Disorders, Bergen, Norway \\ ${ }^{4}$ Madlamarkveien 2a, Hafrsfjord, Norway \\ ${ }^{5}$ Lagårdsveien 91 , Stavanger, Norway \\ ${ }^{6}$ Department of Psychosocial Science, University of Bergen, Bergen, Norway/Centre for Research and Education in Forensic Psychiatry, \\ Haukeland University Hospital, Bergen, Norway \\ ${ }^{7}$ Comprehensive Doctors Medical Group, Arcadia, CA, USA
}

Objective Hyperactivity is a core symptom of attention-deficit hyperactivity disorder (ADHD), but limited information is available on analysis of activity patterns in this disorder. The aim of the study was to analyze motor activity during daily living in adult patients with ADHD.

Methods Patients $(\mathrm{n}=76)$ from the private psychiatric practice of two of the authors were recruited, and were compared to patients with other psychiatric disorders and to normal controls. Actigraphs were used to record motor activity for six days, with one minute intervals, and data were analysed using linear and non-linear mathematical methods.

Results For short recording periods (300 minutes) the activity levels of ADHD patients do not differ from normal controls, but the autocorrelation (lag 1) is lower and Fourier analysis shows higher power in the high frequency range, corresponding to the period from 2-8 min. During recordings for six days there are no significant differences between ADHD patients and the control groups. The combined and inattentive subgroups differ only in the six days recordings. The Fourier analyses show that the combined type has lower power in the high frequency range, corresponding to the period from $4-8$ hours, and in the analysis of rhythms the intra-daily variability is lower, compared to the inattentive type.

Conclusion Adult ADHD patients do not show evidence of hyperactivity, but have levels of activity similar to normal controls. However, on several measures ADHD patients display altered activity patterns, indicating that the regulation of motor activity in this disorder is different from controls.

Psychiatry Investig 2015;12(4):474-482

Key Words ADHD, Motor activity, Actigraph, Autocorrelation, Fourier analysis.

\section{INTRODUCTION}

Attention-deficit hyperactivity disorder (ADHD) is defined by symptoms of hyperactivity, impulsivity and inattention but in addition other symptoms are also prevalent in patients with this disorder, such as mood instability, frustration intolerance

Received: September 15, 2014 Revised: March 18, 2015

Accepted: March 18, 2015 Available online: September 30, 2015

$\triangle$ Correspondence: Ole Bernt Fasmer, MD, PhD

Department of Clinical Medicine, Section for Psychiatry, University of Bergen, Haukeland University Hospital, Bergen N-5021, Norway

Tel: +47 41550327, Fax: +47 55958436, E-mail: ole.fasmer@k1.uib.no

(a) This is an Open Access article distributed under the terms of the Creative Commons Attribution Non-Commercial License (http://creativecommons.org/licenses/by$\mathrm{nc} / 3.0$ ) which permits unrestricted non-commercial use, distribution, and reproduction in any medium, provided the original work is properly cited. and sleep problems. ${ }^{1-3}$ In psychiatric practice these patients are mainly seen in an out-patient setting, and co-morbidity with mood and anxiety disorders is the rule rather than the exception. ${ }^{4}$ The core symptom hyperactivity has a basis in behavioural observations, ${ }^{1}$ but increased activity levels have also been documented with objective registrations using actigraphs ${ }^{5,6}$ and infrared motion analyses. ${ }^{7}$ It is generally assumed that hyperactivity decreases with age, ${ }^{1,4}$ but a recent study in adults described increased motor activity as a more discriminative feature of the disorder than either inattention or impulsivity. ${ }^{7}$ On the other hand, the notion that there is a pervasive hyperactivity in children with ADHD has been questioned. ${ }^{8}$

There is limited information regarding a more detailed analysis of motor activity patterns in ADHD. Teicher ${ }^{5}$ report- 
ed that actigraphically recorded hyperactivity was caused by the absence of quiet periods rather than to periods with increased activity. Mathematical methods such as Fourier analysis, to describe the frequency spectrum, and sample entropy, to measure of the complexity of time series, have been used to characterize the movement pattern of patients with depression and schizophrenia. ${ }^{9,10}$ The aim of the present was to use these methods to study the motor activity of adult ADHD patients. We wanted to analyze data from extended time periods (6 days) and record activity during daily living, since a majority of previous investigations have been performed in a laboratory setting for short (hours) time periods, ${ }^{6}$ and it is conceivable that other patterns may emerge when studying motor activity in a more natural setting.

\section{METHODS}

\section{Ethics statement}

The study protocol was approved by the Norwegian Regional Medical Research Ethics Committee West. Written informed consent was obtained from all participants involved in the study.

\section{Subjects}

Patients were recruited from the private psychiatric practice of KM and WF, both certified psychiatrists with long clinical experience and on contract with the Western Norway Regional Health Authority. The patients were consecutive new referrals, in need of diagnostic evaluation of either ADHD or mood/anxiety disorders, and age between 18 and 65 years.

Exclusion criteria were inability to speak Norwegian and not being able to comply with the study protocol. A total of 104 patients were recruited. For different reasons we were not able to obtain recordings for 27 patients, partly due to logistics problems and partly to patients forgetting to wear the actigraphs. We therefore had 77 actigraph recordings performed. One of the patients had been treated with stimulants during testing and was therefore omitted from the analyses, bringing the number of patients to 76, and these are reported on in the present paper. The group consisted of 35 women and 41 men, and the average age was $37.6 \pm 10.9$ years (mean \pm SD), range $17-61$.

Most of the patients used no psychotropic drugs, $76 \%$ of the ADHD patients and $57 \%$ of the clinical controls. Patients using drugs at referral continued unchangesd with these during the actigraph recordings. A summary of the drugs used is presented in Table 1.

The control group consisted of 20 women and 12 men, average age $38.4 \pm 11.2$ years, range $21-66$, medical students $(n=5)$, patients without serious medical or psychiatric symptoms from a primary care office $(n=4)$ and employees from a psychiatric nursing home $(\mathrm{n}=23)$. None of the control subjects had a history of affective or psychotic symptoms. The controls were recruited during a separate study, using the same actigraph equipment as the patients in this study, and are reported on in two previous papers. ${ }^{9,11}$

\section{Psychiatric assessment}

All diagnostic assessments of the patients were performed by either KM or WF using a standard clinical interview, supplemented when necessary and possible with information from collateral sources. In addition the following assessment instruments were employed:

The Mini-International Neuropsychiatric Interview (MINI Plus, version 5.0.0), a module based semi-structured interview for DSM-IV and ICD-10 diagnoses. ${ }^{12,13}$

The Montgomery-Asberg Depression Rating Scale (MADRS), a standard instrument for the assessment of depression. ${ }^{14}$

Adult ADHD Self-Report Scale (ASRS). This is the World Health Organization's rating scale designed to measure current symptoms of ADHD in adults. It consists of 18 questions that follow the DSM-IV criteria for $\mathrm{ADHD}$, and uses a 5 point scale of $0-4$ ( $0=$ never, $4=$ very often), with a possible range of scores from $0-72$. Items 1-9 cover symptoms of inattention and 10-18 hyperactivity and impulsivity. ${ }^{15-17}$

Wender Utah Rating Scale, 25 questions version (WURS25), a 25-item self-rating scale designed to assess symptoms and signs of ADHD in childhood, using a Likert scale of 0-4 ( $0=$ never, $4=$ very often), yielding a possible score range of $0-$ $100 .^{18}$ WURS-25 has been used in previous studies in Norway. ${ }^{17}$

Mood Disorder Questionnaire (MDQ). This is a screening instrument for bipolar disorder that has been validated both in clinical and control populations. It is a self-report form that consists of 13 questions scored "Yes" of "No". Positive answer to at least 7 questions and confirmation that the symptoms have occurred together and caused problems is suggestive of a bipolar disorder. ${ }^{17,19}$

Cyclothymic temperament scale, a self-report form that consists of 21 questions covering the cyclothymic temperament

Table 1. Psychotropic drug treatment $(\mathrm{N}, \%)$

\begin{tabular}{lcc}
\hline & $\begin{array}{c}\text { ADHD } \\
(\mathrm{N}=41)\end{array}$ & $\begin{array}{c}\text { Clinical controls } \\
(\mathrm{N}=35)\end{array}$ \\
\hline Antidepressants & $8(20 \%)$ & $8(23 \%)$ \\
Anxiolytics & $1(2 \%)$ & $3(9 \%)$ \\
Hypnotics & $1(2 \%)$ & $1(3 \%)$ \\
Antipsychotics & 0 & $2(6 \%)$ \\
Lithium & 0 & $2(6 \%)$ \\
Mood stabilizers except lithium & 0 & $3(9 \%)$ \\
No psychotropic drug treatment & $31(76 \%)$ & $20(57 \%)$ \\
\hline
\end{tabular}

ADHD: attention-deficit hyperactivity disorder 
according to the definition of Akiskal. ${ }^{20,21}$ This scale is part of the larger TEMPS-A autoquestionnaire. ${ }^{22}$

Hospital Anxiety and Depression Scale (HADS). This is a self-assessment form for detecting current states of depression and anxiety, and has been extensively used, also in Norway. ${ }^{23}$

Conner's Continuous Performance Test II, a test frequently used in the evaluation of ADHD. ${ }^{24}$

The final diagnostic evaluation assessment was made after an assessment of all available information, and a consensus diagnosis, based on DSM-IV criteria, was made after discussion of each case (KM, WF, OBF, and JØB).

\section{Recording of motor activity}

Motor activity was monitored with an actigraph worn at the right wrist (Actiwatch, Cambridge Neurotechnology Ltd, England). In the actigraph, activity is measured by using a piezoelectric accelerometer that is programmed to record the integration of intensity, amount and duration of movement in all directions. The sampling frequency is $32 \mathrm{~Hz}$ and movements over $0.05 \mathrm{~g}$ will be recorded. A corresponding voltage is produced and is stored as an activity count in the memory unit of the actigraph. The number of counts is proportional to the intensity of the movement. The right wrist was chosen to make the procedure more convenient for the participants, since most of them have their watches around the left wrist and it is cumbersome to have two such devices on the same arm. Previous studies have shown that there are small differences between the right and left wrist. ${ }^{25,26}$ Total activity counts were recorded for one minute intervals for a period of minimum six days. For each of these actigraph recordings raw data was inspected, and if they contained periods longer than one hour without any activity during daytime (07:00-23:00), the recordings were not used for analyses employing the whole period of six days. ${ }^{27}$

\section{Mathematical analyses}

For all the time periods we calculated seven measures: The mean activity, the standard deviation (SD), expressed as percent of the mean; the root mean square successive differences (RMSSD), expressed as percent of the mean; the relation between RMSSD and SD (RMSSD/SD); the autocorrelation (lag 1); sample entropy and Fourier analysis. The software used for the estimation of sample entropy was from the Physio Toolkit Research Resource for Complex Physiologic signals, ${ }^{28}$ see http://www.physionet.org.

In recordings both from patients and controls there are shorter and more prolonged periods of inactivity. To obtain time series with continuous motor activity we searched manually each recording and selected a period with a length of 300 min, containing not more than 4 consecutive minutes with zero activity, by searching from the start of the recording and using the first period that satisfied this criterion. In this way we were able to obtain 300 min sequences from each participant. In addition data were analysed using information from the whole recording period (six days), with activity counts for one half hour as the unit of measurement. For these time periods we also calculated three additional measures, related to analyses of rhythms.

\section{Sample entropy}

For the analysis of sample entropy the data were normalized, by transforming the time series to have sample mean 0 and sample variance 1 . Sample entropy is a nonlinear measure, indicating the degree of regularity (complexity) of time series, and is the negative natural logarithm of an estimate of the conditional probability that subseries of a certain length that match point-wise, within a tolerance, also match at the next point. We chose the following values, $\mathrm{m}=2$ and $\mathrm{r}=0.2$. Sample entropy was employed since it can be employed with comparatively short time series $(>50)$ and is robust with regard to outliers. ${ }^{29}$

\section{Fourier analysis}

Data were normalized before analysis. No windows were applied. For analysis of the data from the 300 min periods, the first $256 \mathrm{~min}$ were used. Results are presented as variance (\% of the total variance) in four components of the spectrum: $6.5 \times 10^{-5}-0.0010 \mathrm{~Hz}$ (corresponding to the period from 16$256 \mathrm{~min}$ ); $0.0010-0.0021 \mathrm{~Hz}$ (8-16 $\mathrm{min}), 0,0021-0,0042 \mathrm{~Hz}$ (4-8 $\mathrm{min})$, and $0.0042-0.0083 \mathrm{~Hz}(2-4 \mathrm{~min})$. For analysis of data for 6 days, the first 256 half hour periods were used (128 hrs). Results are presented as variance (\% of the total variance) in four components of the spectrum: $1.93 \times 10^{-6}-3.47 \times 10^{-5} \mathrm{~Hz}$ (corresponding to the period from $8-128 \mathrm{hrs}$ ), $3.47 \times 10^{-5}-$ $6.94 \times 10^{-5} \mathrm{~Hz}$ (4-8 hrs), $6.94 \times 10^{-5}-1.39 \times 10^{-4} \mathrm{~Hz}(2-4 \mathrm{hrs})$, and $1.39 \times 10^{-4}-2.78 \times 10^{-4} \mathrm{~Hz}(1-2 \mathrm{hrs})$.

\section{Analyses of rhythms}

Three nonparametric variables developed for analysis of actigraph data were used;

Inter-daily stability (IS), intra-daily variability (IV), and relative amplitude (RA). ${ }^{27}$ The IS quantifies the invariability between the days, that is, the strength of coupling of the rhythm to supposedly stable environmental factors. The IV gives an indication of the fragmentation of the rhythm, that is, the frequency and extent of transitions between rest and activity. RA is calculated using data from the most active 10 $\mathrm{h}$ period and the least active $5 \mathrm{~h}$ period in the average $24 \mathrm{~h}$ pattern. For the analyses of IS, IV and RA data from the whole period of six days were used. 


\section{Statistics}

ANOVA and Student's t-test were employed to evaluate differences between groups, with the p-value set at 0.05 . For the ANOVA analyses post hoc Bonferroni tests were used to compare ADHD or clinical controls with the normal controls. SPSS version 18 was used for the statistical analyses.

\section{RESULTS}

After a comprehensive evaluation and consensus discussion, 41 patients received a diagnosis of $\mathrm{ADHD}$, and 35 were deemed not to fulfill the criteria for ADHD, and all were given other psychiatric diagnoses (clinical controls). The gender ratio (female/male) is, 17/24 in the ADHD group and 18/17 in the clinical control group. The mean age is similar in the two groups ( $37.2 \pm 10.8$ vs. $38.0 \pm 11.2$ years).

In Table 2 the clinical characteristics of the two groups are shown. The ADHD group has substantially higher scores on both the WURS and ASRS scales than the controls, and, apart from the reaction time, results from the continuous performance test are also clearly different in the two groups. For the questionnaires and the MADRS scale there are no significant differences between the groups. All but seven of the ADHD patients also had another psychiatric diagnosis. There are a higher number of patients with anxiety disorders in the group without $\mathrm{ADHD}$, but for the other diagnosis groups there are no significant differences between the groups.

In the ADHD group 18 patients fulfilled criteria for the combined subtype and 23 for the inattentive type. The patients with the combined type have higher scores on the WURS scale, but apart from that there are no significant differences between the groups (Table 3).

In Figure 1 are shown an actigraph recording from an $\mathrm{ADHD}$ patient (during seven days), and in Figure $2 \mathrm{~A}$ the activity profile from a $300 \mathrm{~min}$ sequence with continuous motor activity. In Table 4 the results from actigraphic recordings of 300 min periods with continuous motor activity are presented. The mean activity level, SD, RMSSD, the RMSSD/SD ratio, and the sample entropy, are not significantly different across the three groups. However, the autocorrelation is lower in the ADHD group, compared to the normal controls.

Fourier analysis of these 300 min sequences (Figure 2B) also revealed clear differences between the groups, with the ADHD group showing higher power in the high frequency range,

Table 2. Characteristics of the clinical samples

\begin{tabular}{|c|c|c|c|}
\hline & $\operatorname{ADHD}(\mathrm{N}=41)^{*}$ & Clinical controls $(\mathrm{N}=35)^{*}$ & $\mathrm{p}$ \\
\hline WURS (mean $\pm S D)$ & $50.0 \pm 20.0$ & $30.6 \pm 15.9$ & $<0.001$ \\
\hline ASRS $($ mean $\pm S D)$ & $47.7 \pm 13.1$ & $32.7 \pm 12.7$ & $<0.001$ \\
\hline \multicolumn{4}{|l|}{ HADS } \\
\hline Depression $($ mean $\pm \mathrm{SD})$ & $4.3 \pm 3.8$ & $5.4 \pm 4.0$ & NS \\
\hline Anxiety $($ mean $\pm S D)$ & $9.2 \pm 4.7$ & $9.5 \pm 4.7$ & NS \\
\hline MADRS (mean \pm SD) & $13.3 \pm 7.7$ & $14.7 \pm 8.3$ & NS \\
\hline MDQ $($ mean $\pm S D)$ & $5.5 \pm 5.3$ & $5.3 \pm 5.4$ & NS \\
\hline $\mathrm{CT}(\mathrm{mean} \pm \mathrm{SD})$ & $11.7 \pm 4.7$ & $11.2 \pm 4.0$ & NS \\
\hline \multicolumn{4}{|l|}{ Continuous performance test (ms) } \\
\hline Reaction time & $370 \pm 95$ & $381 \pm 61$ & NS \\
\hline Omissions & $3.2 \pm 4.8$ & $0.9 \pm 1.23$ & 0.007 \\
\hline Commisions & $56.3 \pm 23.2$ & $36.7 \pm 16.8$ & $<0.001$ \\
\hline Variability & $12.6 \pm 10.0$ & $6.7 \pm 4.9$ & 0.002 \\
\hline Bipolar disorder (\%) & 34 & 49 & NS \\
\hline Unipolar depression (\%) & 34 & 26 & NS \\
\hline Anxiety disorder (\%) & 37 & 63 & 0.022 \\
\hline Alcohol or drug abuse (\%) & 22 & 14 & NS \\
\hline Other diagnoses (\%) & 22 & 37 & NS \\
\hline Any diagnosis, apart from $\mathrm{ADHD}(\%)$ & 85 & 100 & \\
\hline Number of diagnoses, apart from ADHD & $1.5 \pm 1.0$ & $1.9 \pm 0.8$ & \\
\hline
\end{tabular}

*the number of patients in each group varies somewhat for the different questionnaires and tests. Student's t-test or chi-square test were used to compare the two groups. ADHD: attention-deficit hyperactivity disorder, WURS: Wender Utah Rating Scale, ASRS: Adult ADHD Self-Report Scale, HADS: Hospital Anxiety and Depression Scale, MDQ: Mood Disorder Questionnaire, CT: Cyclothymic temperament scale, NS: not significant 
Table 3. Characteristics of the two ADHD subtypes, combined and inattentive

\begin{tabular}{|c|c|c|c|}
\hline & Combined type $(\mathrm{N}=18)^{*}$ & Inattentive type $(\mathrm{N}=23)^{*}$ & $\mathrm{p}$ \\
\hline Gender (f/m) & $8 / 10$ & $9 / 14$ & NS \\
\hline Age & $37.6 \pm 10.4$ & $36.8 \pm 11.3$ & NS \\
\hline WURS & $60.0 \pm 20.2$ & $42.6 \pm 16.7$ & 0.005 \\
\hline ASRS & $52.2 \pm 13.9$ & $44.3 \pm 11.7$ & NS \\
\hline \multicolumn{4}{|l|}{ HADS } \\
\hline Depression & $4.0 \pm 4.1$ & $4.5 \pm 3.6$ & NS \\
\hline Anxiety & $10.0 \pm 5.4$ & $8.6 \pm 4.2$ & NS \\
\hline MADRS & $13.1 \pm 7.0$ & $13.5 \pm 8.4$ & NS \\
\hline MDQ & $5.8 \pm 5.2$ & $5.2 \pm 5.5$ & NS \\
\hline CT & $12.4 \pm 4.6$ & $11.0 \pm 4.9$ & NS \\
\hline \multicolumn{4}{|l|}{ Continuous performance test } \\
\hline Reaction time & $404 \pm 122$ & $343 \pm 57$ & NS \\
\hline Omissions & $4.0 \pm 6.3$ & $2.5 \pm 3.2$ & NS \\
\hline Commisions & $53.6 \pm 23.6$ & $58.3 \pm 23.2$ & NS \\
\hline Variability & $13.4 \pm 10.0$ & $12.1 \pm 10.2$ & NS \\
\hline Bipolar disorder (\%) & 33 & 35 & NS \\
\hline Unipolar depression (\%) & 22 & 43 & NS \\
\hline Anxiety disorder (\%) & 28 & 43 & NS \\
\hline Alcohol or drug abuse (\%) & 33 & 13 & NS \\
\hline Other psychiatric diagnoses (\%) & 28 & 17 & NS \\
\hline Any comorbidity (\%) & 83 & 87 & NS \\
\hline Number of comorbid disorders & $1.5 \pm 1.1$ & $1.5 \pm 0.9$ & NS \\
\hline
\end{tabular}

*the number of patients in each group varies somewhat for the different questionnaires and tests. Student's t-test or chi-square test were used to compare the two groups. ADHD: attention-deficit hyperactivity disorder, WURS: Wender Utah Rating Scale, ASRS: Adult ADHD Self-Report Scale, HADS: Hospital Anxiety and Depression Scale, MDQ: Mood Disorder Questionnaire, CT: Cyclothymic temperament scale, NS: not significant

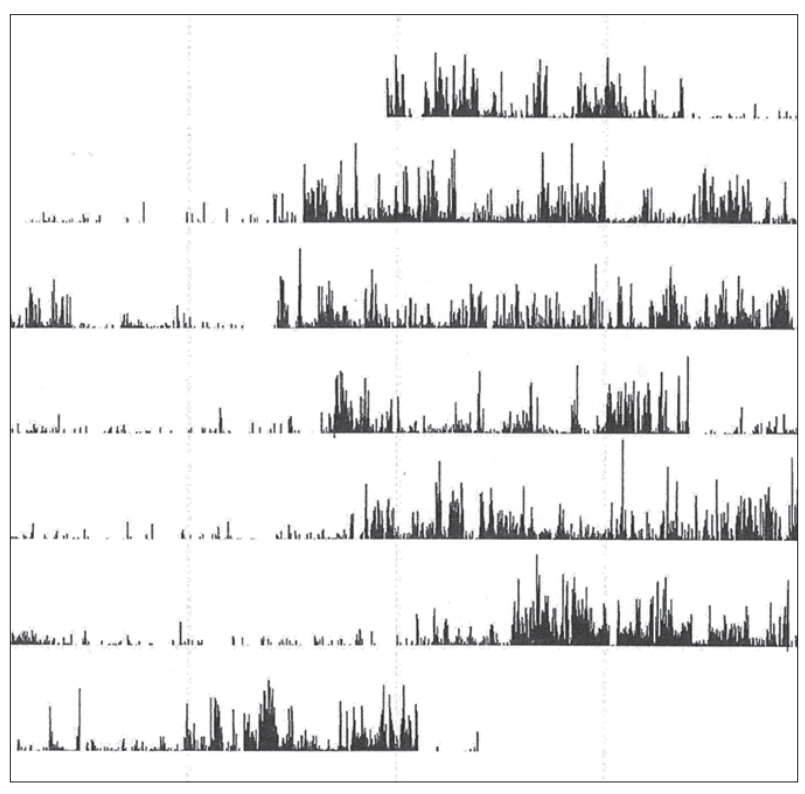

Figure 1. Actigraph recording from an attention-deficit hyperactivity disorder patient. corresponding to the periods of $2-4$ and $4-8$ min (Table 5).

When analyzing actigraphic recordings for six days we were able to use data from 32 patients with ADHD, 29 clinical controls and 20 normal controls. There were no significant differences between the three groups for any of the measures analyzed (data not shown).

Comparing the two ADHD subgroups reveals no significant differences with regard to analyses of the $300 \mathrm{~min}$ recordings. Concerning the six days recordings the mean activity, SD, RMSSD, RMSSD/SD, autocorrelation and sample entropy are not significantly different (data not shown), but in the Fourier analysis the combined type have lower power in the high frequency range, and this is significant for the $6.94 \times 10^{-5}-1.39 \times 10^{-4} \mathrm{~Hz}$ frequency range, corresponding to the time period 2-4 hours, with higher power in the $1.93 \times$ $10^{-6}-3.47 \times 10^{-5} \mathrm{~Hz}$ frequency range, corresponding to the period from 8-128 hrs. In addition the rhythm analyses show that the combined type also has a significantly lower intradaily variability compared to the inattentive type (Table 6). 


\section{DISCUSSION}

Using objective registration of motor activity during daily living we have not been able to find any evidence of pervasive hyperactivity in adult patients with $\mathrm{ADHD}$, either in continuous periods with motor activity or in total activity counts during six days. However, on several measures ADHD patients display altered activity patterns, indicating that the regulation of motor activity is indeed altered in this disorder. For periods with continuous motor activity, using a recording period of one minute, the ADHD patients are character- ized by increased variability in the high frequency part of the spectrum, corresponding to the periods from 2-8 $\mathrm{min}$ in the Fourier analysis, and at the same time the autocorrelation (lag 1) is reduced. The RMSSD/SD ratio is increased compared to normal controls, but not significantly so. The clinical controls have values on these measures between the normal controls and the ADHD patients. We have seen a similar pattern of motor variability changes assessed with actigraphs in patients with schizophrenia; ${ }^{9,10}$ and in healthy controls given the NMDA-antagonist memantine, ${ }^{10}$ indicating that altered motor activity in patients with schizophrenia may be related
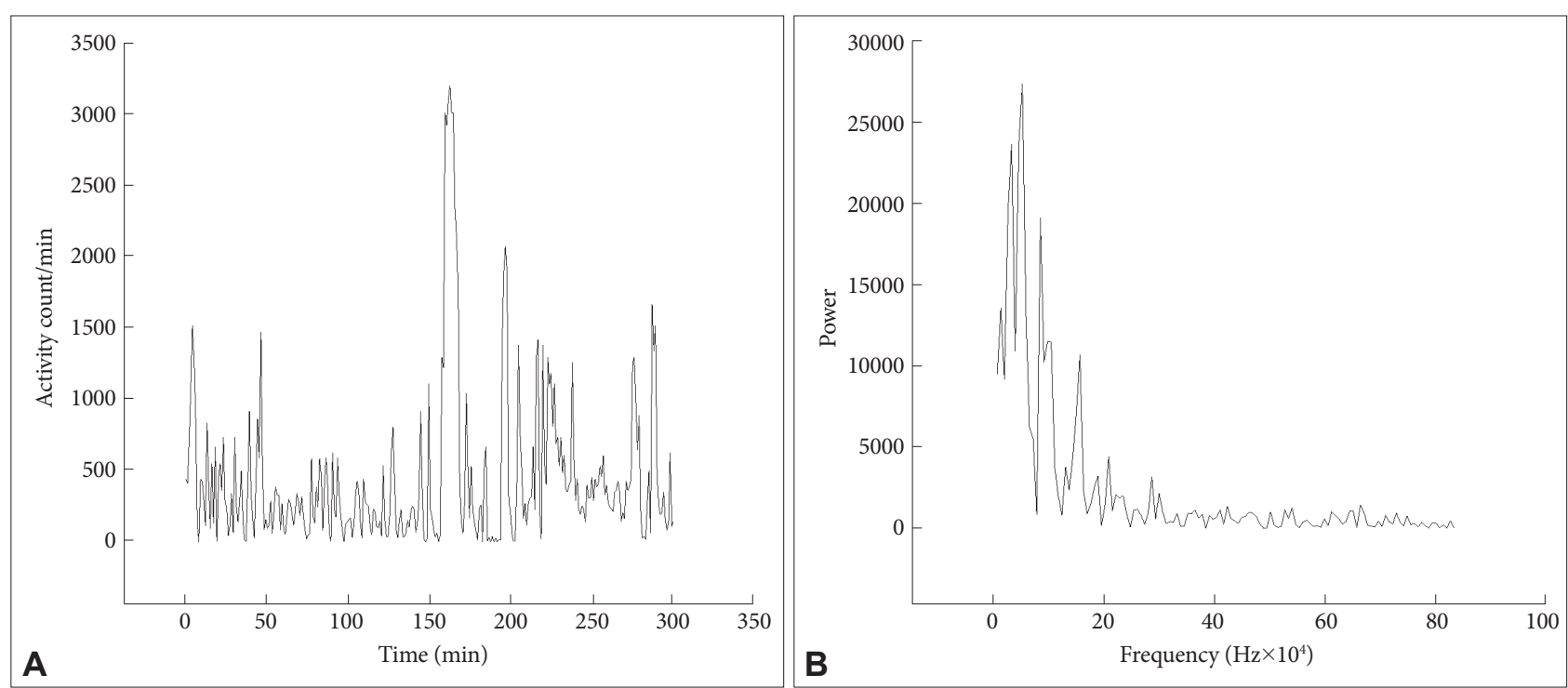

Figure 2. A and B: Activity counts during $300 \mathrm{~min}$ from an ADHD patient. Fourier analysis of a 256 min recording (from the actigraph recording in A). ADHD: attention-deficit hyperactivity disorder.

Table 4. Results from actigraphic recordings of 300 min periods with continuous motor activity

\begin{tabular}{lcccc}
\hline & ADHD $(\mathrm{N}=41)$ & Clinical controls $(\mathrm{N}=35)$ & Controls $(\mathrm{N}=32)$ & ANOVA \\
\hline Mean activity & $414 \pm 194$ & $411 \pm 222$ & $479 \pm 208$ & $\mathrm{~F}(105,2)=1.167, \mathrm{p}=0.315$ \\
SD & $95.0 \pm 19.2$ & $93.2 \pm 27.1$ & $90.9 \pm 19.8$ & $\mathrm{~F}(105,2)=0.300, \mathrm{p}=0.741$ \\
RMSSD & $84.0 \pm 18.9$ & $81.7 \pm 23.6$ & $76.1 \pm 17.9$ & $\mathrm{~F}(105,2)=1.431, \mathrm{p}=0.244$ \\
RMSSD/SD & $0.908 \pm 0.153$ & $0.887 \pm 0.123$ & $0.841 \pm 0.010$ & $\mathrm{~F}(105,2)=2.458, \mathrm{p}=0.091$ \\
Autocorrelation & $0.572 \pm 0.135^{*}$ & $0.591 \pm 0.114$ & $0.648 \pm 0.080$ & $\mathrm{~F}(105,2)=4.252, \mathrm{p}=0.017$ \\
Sample entropy & $1.150 \pm 0.319$ & $1.189 \pm 0.410$ & $1.129 \pm 0.299$ & $\mathrm{~F}(105,2)=0.266, \mathrm{p}=0.767$ \\
\hline
\end{tabular}

${ }^{*} \mathrm{p}<0.05$. SD and RMSSD are given in \% of mean activity level. Post hoc Bonferroni test (ADHD or clinical controls vs. normal controls). ADHD: attention-deficit hyperactivity disorder, SD: standard deviation, RMSSD: root mean square successive differences, ANOVA: analysis of variance

Table 5. Fourier analysis of the actigraphic recordings of 300 min with continuous motor activity

\begin{tabular}{lcccc}
\hline \multicolumn{1}{c}{ Period } & ADHD $(\mathrm{N}=41)$ & Clinical controls $(\mathrm{N}=35)$ & Controls $(\mathrm{N}=32)$ & ANOVA \\
\hline $2-4 \mathrm{~min}$ & $0.189 \pm 0.061^{*}$ & $0.182 \pm 0.063$ & $0.154 \pm 0.050$ & $\mathrm{~F}(105,2)=3.473, \mathrm{p}=0.035$ \\
$4-8 \mathrm{~min}$ & $0.185 \pm 0.054^{* * *}$ & $0.168 \pm 0.045^{*}$ & $0.138 \pm 0.039$ & $\mathrm{~F}(105,2)=8.991, \mathrm{p}<0.001$ \\
$8-16 \mathrm{~min}$ & $0.164 \pm 0.050$ & $0.168 \pm 0.056$ & $0.147 \pm 0.047$ & $\mathrm{~F}(105,2)=1.654, \mathrm{p}=0.196$ \\
$16-256 \mathrm{~min}$ & $0.463 \pm 0.125^{* *}$ & $0.481 \pm 0.107^{*}$ & $0.562 \pm 0.098$ & $\mathrm{~F}(105,2)=7.657, \mathrm{p}=0.001$ \\
\hline
\end{tabular}

${ }^{*} \mathrm{p}<0.05,{ }^{* *} \mathrm{p}<0.01,{ }^{* * *} \mathrm{p}<0.001$. Post hoc Bonferroni test (ADHD or clinical controls vs. normal controls). ADHD: attention-deficit hyperactivity disorder, ANOVA: analysis of variance 
Table 6. Fourier analysis and analyses of rhythms of the actigraphic recordings for six days

\begin{tabular}{|c|c|c|c|}
\hline Fourier analysis & Combined type $(\mathrm{N}=13)$ & Inattentive type $(\mathrm{N}=19)$ & $\mathrm{p}$ \\
\hline \multicolumn{4}{|l|}{ Period } \\
\hline $1-2 \mathrm{hrs}$ & $0.163 \pm 0.049$ & $0.166 \pm 0.039$ & NS \\
\hline $2-4 \mathrm{hrs}$ & $0.149 \pm 0.033$ & $0.169 \pm 0.037$ & NS \\
\hline $4-8 \mathrm{hrs}$ & $0.113 \pm 0.035$ & $0.143 \pm 0.037$ & 0.029 \\
\hline $8-128 \mathrm{hrs}$ & $0.576 \pm 0.090$ & $0.522 \pm 0.080$ & NS \\
\hline \multicolumn{4}{|l|}{ Analyses of rhythms } \\
\hline Interdaily stability & $0.533 \pm 0.097$ & $0.493 \pm 0.076$ & NS \\
\hline Intradaily variability & $0.739 \pm 0.190$ & $0.895 \pm 0.158$ & 0.017 \\
\hline Relative amplitude & $0.830 \pm 0.096$ & $0.856 \pm 0.107$ & NS \\
\hline
\end{tabular}

NS: not significant

to changes in NMDA receptor function. An example of timedependent changes in variability pattern in ADHD is the findings of Castellanos et al. $^{30}$ that oscillations in the reaction time of $\mathrm{ADHD}$ patients were different from controls, with a frequency of $0.05 \mathrm{~Hz}$ (cycle length $20 \mathrm{sec}$ ). They attributed this to altered catecholaminergic neurotransmission. Most of the neurochemical changes found in ADHD are related to dopaminergic systems, ${ }^{31}$ but with regard to the close interaction between glutamate and dopamine in the brain ${ }^{32}$ and the possibility that glutaminergic systems are affected in $\mathrm{ADHD}^{33}$ we may speculate that similar changes in NMDA receptor function are related to the motor disturbances in ADHD. In schizophrenic patients, in addition to the changes in variability, sample entropy was increased compared both to controls and to depressed patients, ${ }^{9}$ while administration of memantine did not influence sample entropy values. ${ }^{10}$ In the present study we found no change in this measure of complexity, neither in the ADHD patients nor in the clinical controls. We are not aware of other studies that have used this method (or others) to measure the degree of order or complexity in time series of motor activity.

When analyzing the whole period of six days, using sequences of 30 minutes, we did not find any significant differences between ADHD patients and the two control groups. These data therefore show that changes in variability differ, depending on the time frame used to analyze data. A pattern of reduced total activity and increased SD was found in depressed patients in our previous study, ${ }^{9}$ and increased variability of motor activity has been described by Wood et al. ${ }^{34}$ in children with the combined type of ADHD. Increased intra-individual variability has also been found in different neuropsychological tests in patients with $\mathrm{ADHD},{ }^{35}$ depression and schizophrenia, ${ }^{36}$ and in registration of mood in depressed patients. ${ }^{37}$ Alterations in variability patterns are therefore not limited to one diagnostic category or one test method, but increased intra-individual variability has been suggested to be related to cognitive decline in the elderly and to degenerative brain disorders, ${ }^{38}$ and possibly connected with alterations in dopaminergic systems. ${ }^{39}$

Pervasive hyperactivity is a defining characteristic of $\mathrm{ADHD},{ }^{4}$ and increased motor activity has been documented in children with ADHD using objective measures, such as actigraphs, mostly during short, ${ }^{6,34,40-42}$ but also with more prolonged recording periods. ${ }^{5,43,44}$ Similarly, hyperactivity of children with ADHD has been documented in laboratory settings using infrared motion analysis. ${ }^{45}$ Increased motor activity has also been found in adult patients with ADHD, mostly during short recordings, connected with neuropsychological testing, ${ }^{7,46,47}$ but also in a week-long study. ${ }^{48}$ In addition, treatment both with methylphenidate and atomoxetine has been shown to reduce hyperactivity. ${ }^{46,49,50}$ However, the notion that there is a continuous hyperactivity in ADHD patients has been challenged by Licht and Tryon who found that only one of nine children diagnosed with the combined form of ADHD was pervasively hyperactive. ${ }^{8}$ The present results are compatible with those findings. Furthermore, Teicher ${ }^{5}$ notes that increased activity of children with ADHD are due more to the absence of quiescent periods than to periods with high activity.

The lack of difference between the combined and the inattentive types of ADHD for most of the activity measures, including total activity counts, is in agreement with the finding of Dane et al. ${ }^{42}$ that activity scores in children, measured with actigraphs, did not distinguish between these subtypes. Similarly, Teicher ${ }^{7}$ using infrared motion analysis in adult ADHD patients did not find any difference in degree of hyperactivity between the two types. However, there are two measures where the two ADHD subtypes differ in our study. For the whole period of six days, using sequences of 30 minutes, Fourier analysis shows that, compared to the inattentive type, the combined type has significantly lower power in the frequency range corresponding to the period of 4-8 hours, and 
at the same time the intradaily variability, using van Someren's rhythm analysis ${ }^{27}$ is lower. The intra-daily variability is calculated using one hour time intervals and is therefore in broad agreement with the Fourier analysis results. Together these findings indicate differences in organization of motor activity between the two subtypes, with the combined type having a less variable pattern, in the time range of a few hours. Boonstra et al., ${ }^{48}$ using the same analysis method, also found that adult ADHD patients, all with the combined or hyperactive form of ADHD, had reduced intra-daily variability. However, in addition they found increased inter-daily stability, both of these findings indicating a more stable and less variable motor activity pattern. This pattern of reduced intra-daily variability and increased inter-daily stability is similar to what we found in the sample of schizophrenic patients described above. $^{11}$

Actigraph recording is of course giving only a crude measure of activity level, compared to a more detailed analysis using infrared motion analysis. However, as documented above, hyperactivity has previously been found using both types of equipment, so we do not think that our inability to find evidence of hyperactivity is due to our choice of actigraphs for measurement. Additionally, to be able to study activity level over more prolonged time periods and in daily living actigraphs are more convenient.

The patients recruited for the present study are not necessarily representative of ADHD patients in the general population. Most of them have other psychiatric disorders and it is therefore difficult to disentangle the contribution of ADHD from the effect of these other conditions. On the other hand, comorbidity is the rule rather than the exceptions when meeting these patients in an adult psychiatric setting, and also in epidemiological studies the rate of comorbidity is high. ${ }^{4} \mathrm{We}$ therefore think that the study group may be representative for adult ADHD patients presenting for evaluation in a psychiatric out-patient clinic.

Even though the clinical interviews were performed by two different psychiatrists, the use of the same diagnostic instruments and a final evaluation of each case by four experienced psychiatrists make it likely that we have obtained a reasonable accurate diagnostic assessment for the whole study sample.

\section{Conclusion}

Using actigraphic assessment of motor activity in adult ADHD patients do not show any evidence of hyperactivity, but these patients have levels of activity similar to normal controls. However, using one minute recording periods, we find a pattern of variability similar to previous findings in schizophrenic patients and in healthy controls given the
NMDA-antagonist memantine, indicating that motor activity in ADHD is altered, possibly related to changes in glutamatergic neurotransmission. The combined subtype differ from the inattentive type in having a less variable activity pattern in the time range of hours, again similar to what we have seen in schizophrenic patients. These results underscore the importance of further studies related to the function of motor systems in this common neurodevelopmental disorder.

\section{Acknowledgments}

This research has been supported by the Norwegian Resource Center for ADHD, Tourette Syndrome and Narcolepsy.

\section{REFERENCES}

1. American Psychiatric Association. Diagnostic and Statistical Manual of Mental Disorders, 4th edition-Text Revision. Washington DC: American Psychiatric Association; 2000.

2. Cho H, Ji S, Chung S, Kim M, Joung YS. Motor function in schoolaged children with attention-deficit/hyperactivity disorder in Korea. Psychiatry Investig 2014;11:223-227.

3. Di Trani M, Di Roma F, Andriola E, Leone D, Parisi P, Miano S, et al. Comorbid depressive disorders in ADHD: the role of ADHD severity, subtypes and familial psychiatric disorders. Psychiatry Investig 2014; 11:137-142.

4. Haavik J, Halmoy A, Lundervold AJ, Fasmer OB. Clinical assessment and diagnosis of adults with attention-deficit/hyperactivity disorder. Expert Rev Neurother 2010;10:1569-1580.

5. Teicher MH. Actigraphy and motion analysis: new tools for psychiatry. Harv Rev Psychiatry 1995;3:18-35.

6. Alderson RM, Rapport MD, Kasper LJ, Sarver DE, Kofler MJ. Hyperactivity in boys with attention deficit/hyperactivity disorder (ADHD): the association between deficient behavioral inhibition, attentional processes, and objectively measured activity. Child Neuropsychol 2012; 18:487-505.

7. Teicher MH, Polcari A, Fourligas N, Vitaliano G, Navalta CP. Hyperactivity persists in male and female adults with $\mathrm{ADHD}$ and remains a highly discriminative feature of the disorder: a case-control study. BMC Psychiatry 2012;12:190.

8. Licht CA, Tryon WW. Are children diagnosed with the combined form of ADHD pervasively hyperactive? Behav Modif 2009;33:655-681.

9. Hauge ER, Berle JO, Oedegaard KJ, Holsten F, Fasmer OB. Nonlinear analysis of motor activity shows differences between schizophrenia and depression: a study using Fourier analysis and sample entropy. PLoS One 2011;6:e16291.

10. Johnsen E, Fasmer OB, van Wageningen H, Hugdahl K, Hauge E, Jørgensen HA. The influence of glutaminergic antagonism on motor variability, and comparison to findings in schizophrenia patients. Acta Neuropsychiatr 2013;25:105-112.

11. Berle JO, Hauge ER, Oedegaard KJ, Holsten F, Fasmer OB. Actigraphic registration of motor activity reveals a more structured behavioural pattern in schizophrenia than in major depression. BMC Res Notes 2010; 3:149.

12. Sheehan DV, Lecrubier Y, Sheehan KH, Amorim P, Janavs J, Weiller E, et al. The Mini-International Neuropsychiatric Interview (M.I.N.I.): the development and validation of a structured diagnostic psychiatric interview for DSM-IV and ICD-10. J Clin Psychiatry 1998;59(Suppl 20):2233; quiz 34-57.

13. Leiknes KA, Malt U, Malt EA, Leganger S. The Mini-International Neuropsychiatric Interview Plus. Norwegian version. Oslo: Psykosomatisk avdeling, Rikshospitalet; 2005.

14. Montgomery SA, Asberg M. A new depression scale designed to be sensitive to change. Br J Psychiatry 1979;134:382-389. 
15. Kessler RC, Adler L, Ames M, Demler O, Faraone S, Hiripi E, et al. The World Health Organization Adult ADHD Self-Report Scale (ASRS): a short screening scale for use in the general population. Psychol Med 2005; 35:245-256.

16. Kessler RC, Adler L, Barkley R, Biederman J, Conners CK, Demler O, et al. The prevalence and correlates of adult ADHD in the United States: results from the National Comorbidity Survey Replication. Am J Psychiatry 2006;163:716-723.

17. Halmoy A, Fasmer OB, Gillberg C, Haavik J. Occupational outcome in adult ADHD: impact of symptom profile, comorbid psychiatric problems, and treatment: a cross-sectional study of 414 clinically diagnosed adult ADHD patients. J Atten Disord 2009;13:175-187.

18. Ward MF, Wender PH, Reimherr FW. The Wender Utah Rating Scale: an aid in the retrospective diagnosis of childhood attention deficit hyperactivity disorder. Am J Psychiatry 1993;150:885-890.

19. Hirschfeld RM, Williams JB, Spitzer RL, Calabrese JR, Flynn L, Keck PE $\mathrm{Jr}$, et al. Development and validation of a screening instrument for bipolar spectrum disorder: the Mood Disorder Questionnaire. Am J Psychiatry 2000;157:1873-1875.

20. Akiskal HS, Akiskal KK, Haykal RF, Manning JS, Connor PD. TEMPSA: progress towards validation of a self-rated clinical version of the Temperament Evaluation of the Memphis, Pisa, Paris, and San Diego Autoquestionnaire. J Affect Disord 2005;85:3-16.

21. Landaas ET, Halmoy A, Oedegaard KJ, Fasmer OB, Haavik J. The impact of cyclothymic temperament in adult ADHD. J Affect Disord 2012;142: 241-247.

22. Akiskal HS, Akiskal K, Allilaire JF, Azorin JM, Bourgeois ML, Sechter D, et al. Validating affective temperaments in their subaffective and socially positive attributes: psychometric, clinical and familial data from a French national study. J Affect Disord 2005;85:29-36.

23. Oedegaard KJ, Neckelmann D, Mykletun A, Dahl AA, Zwart JA, Hagen $\mathrm{K}$, et al. Migraine with and without aura: association with depression and anxiety disorder in a population-based study. The HUNT Study. Cephalalgia 2006;26:1-6.

24. Nichols SL, Waschbusch DA. A review of the validity of laboratory cognitive tasks used to assess symptoms of ADHD. Child Psychiatry Hum Dev 2004;34:297-315.

25. Van Hilten JJ, Middelkoop HA, Kuiper SI, Kramer CG, Roos RA. Where to record motor activity: an evaluation of commonly used sites of placement for activity monitors. Electroencephalogr Clin Neurophysiol 1993; 89:359-362.

26. Littner M, Hirshkowitz M, Davila D, Anderson WM, Kushida CA, Woodson BT, et al. Practice parameters for the use of auto-titrating continuous positive airway pressure devices for titrating pressures and treating adult patients with obstructive sleep apnea syndrome. An American Academy of Sleep Medicine report. Sleep 2002;25:143-147.

27. Van Someren EJ, Swaab DF, Colenda CC, Cohen W, McCall WV, Rosenquist PB. Bright light therapy: improved sensitivity to its effects on rest-activity rhythms in Alzheimer patients by application of nonparametric methods. Chronobiol Int 1999;16:505-518.

28. Goldberger AL, Amaral LA, Glass L, Hausdorff JM, Ivanov PC, Mark RG, et al. PhysioBank, PhysioToolkit, and PhysioNet: components of a new research resource for complex physiologic signals. Circulation 2000;101: E215-E220,

29. Richman JS, Moorman JR. Physiological time-series analysis using approximate entropy and sample entropy. Am J Physiol Heart Circ Physiol 2000;278:H2039-H2049.

30. Castellanos FX, Sonuga-Barke EJ, Scheres A, Di Martino A, Hyde C, Walters JR. Varieties of attention-deficit/hyperactivity disorder-related intra-individual variability. Biol Psychiatry 2005;57:1416-1423.

31. Johansson S, Halleland H, Halmoy A, Jacobsen KK, Landaas ET, Dramsdahl M, et al. Genetic analyses of dopamine related genes in adult ADHD patients suggest an association with the DRD5-microsatellite repeat, but not with DRD4 or SLC6A3 VNTRs. Am J Med Genet B Neuropsychiatr Genet 2008;147B:1470-1475.

32. Dickerson JW, Conn PJ. Therapeutic potential of targeting metabotropic glutamate receptors for Parkinson's disease. Neurodegener Dis
Manag 2012;2:221-232.

33. Lesch KP, Merker S, Reif A, Novak M. Dances with black widow spiders: dysregulation of glutamate signalling enters centre stage in ADHD. Eur Neuropsychopharmacol 2013;23:479-491.

34. Wood AC, Asherson P, Rijsdijk F, Kuntsi J. Is overactivity a core feature in ADHD? Familial and receiver operating characteristic curve analysis of mechanically assessed activity level. J Am Acad Child Adolesc Psychiatry 2009;48:1023-1030.

35. Russell VA, Oades RD, Tannock R, Killeen PR, Auerbach JG, Johansen $\mathrm{EB}$, et al. Response variability in attention-deficit/hyperactivity disorder: a neuronal and glial energetics hypothesis. Behav Brain Funct 2006;2:30.

36. Kaiser S, Roth A, Rentrop M, Friederich HC, Bender S, Weisbrod M. Intra-individual reaction time variability in schizophrenia, depression and borderline personality disorder. Brain Cogn 2008;66:73-82.

37. Woyshville MJ, Lackamp JM, Eisengart JA, Gilliland JA. On the meaning and measurement of affective instability: clues from chaos theory. Biol Psychiatry 1999;45:261-269.

38. MacDonald SW, Nyberg L, Backman L. Intra-individual variability in behavior: links to brain structure, neurotransmission and neuronal activity. Trends Neurosci 2006;29:474-480.

39. MacDonald SW, Cervenka S, Farde L, Nyberg L, Backman L. Extrastriatal dopamine D2 receptor binding modulates intraindividual variability in episodic recognition and executive functioning. Neuropsychologia 2009;47:2299-2304.

40. Kam HJ, Shin YM, Cho SM, Kim SY, Kim KW, Park RW. Development of a decision support model for screening attention-deficit hyperactivity disorder with actigraph-based measurements of classroom activity. Appl Clin Inform 2010;1:377-393.

41. Rapport MD, Bolden J, Kofler MJ, Sarver DE, Raiker JS, Alderson RM. Hyperactivity in boys with attention-deficit/hyperactivity disorder (ADHD): a ubiquitous core symptom or manifestation of working memory deficits? J Abnorm Child Psychol 2009;37:521-534.

42. Dane AV, Schachar RJ, Tannock R. Does actigraphy differentiate ADHD subtypes in a clinical research setting? J Am Acad Child Adolesc Psychiatry 2000;39:752-760.

43. Porrino LJ, Rapoport JL, Behar D, Sceery W, Ismond DR, Bunney WE Jr. A naturalistic assessment of the motor activity of hyperactive boys. I. Comparison with normal controls. Arch Gen Psychiatry 1983;40:681687.

44. Tsujii N, Okada A, Kaku R, Kuriki N, Hanada K, Matsuo J, et al. Association between activity level and situational factors in children with attention deficit/hyperactivity disorder in elementary school. Psychiatry Clin Neurosci 2007;61:181-185.

45. Teicher MH, Ito Y, Glod CA, Barber NI. Objective measurement of hyperactivity and attentional problems in ADHD. J Am Acad Child Adolesc Psychiatry 1996;35:334-342.

46. Ginsberg Y, Hirvikoski T, Grann M, Lindefors N. Long-term functional outcome in adult prison inmates with ADHD receiving OROS-methylphenidate. Eur Arch Psychiatry Clin Neurosci 2012;262:705-724.

47. Lis S, Baer N, Stein-en-Nosse C, Gallhofer B, Sammer G, Kirsch P. Objective measurement of motor activity during cognitive performance in adults with attention-deficit/hyperactivity disorder. Acta Psychiatr Scand 2010;122:285-294.

48. Boonstra AM, Kooij JJ, Oosterlaan J, Sergeant JA, Buitelaar JK, Van Someren EJ. Hyperactive night and day? Actigraphy studies in adult ADHD: a baseline comparison and the effect of methylphenidate. Sleep 2007;30:433-442.

49. Porrino LJ, Rapoport JL, Behar D, Ismond DR, Bunney WE Jr. A naturalistic assessment of the motor activity of hyperactive boys. II. Stimulant drug effects. Arch Gen Psychiatry 1983;40:688-693.

50. Wehmeier PM, Schacht A, Wolff C, Otto WR, Dittmann RW, Banaschewski T. Neuropsychological outcomes across the day in children with attention-deficit/hyperactivity disorder treated with atomoxetine: results from a placebo-controlled study using a computer-based continuous performance test combined with an infra-red motion-tracking device. J Child Adolesc Psychopharmacol 2011;21:433-444. 